\title{
Cercarial Dermatitis at Public Bathing Sites (Region Zealand, Denmark): A Case Series and Literature Review
}

\author{
Azmi Al-Jubury ${ }^{a} \quad$ Anette Bygum $^{\text {b, c }}$ Eva SusannaTracz ${ }^{d}$ Charlotte \\ Näslund Koch ${ }^{\mathrm{e}}$ Kurt Buchmann ${ }^{\mathrm{a}}$ \\ aDepartment of Veterinary and Animal Sciences, Laboratory of Aquatic Pathobiology, \\ Faculty of Health and Medical Sciences, University of Copenhagen, Frederiksberg, Denmark; \\ ${ }^{b}$ Department of Clinical Genetics, Odense University Hospital, Odense, Denmark; ' $C$ Clinical \\ Institute, University of Southern Denmark, Odense, Denmark; dDepartment of Dermatology,

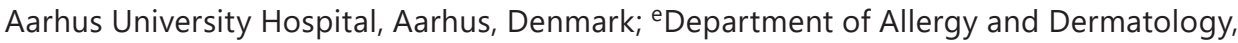 \\ Copenhagen University Hospital, Herlev and Gentofte Hospital, Copenhagen, Denmark
}

\section{Keywords}

Cercarial dermatitis · Swimmer's itch · Avian schistosomes

\section{Abstract}

During recent years, we have observed an increasing occurrence of cercarial dermatitis in Denmark. We here describe 5 new cases from 2019 to 2020 associated with bathing in lakes Esrum $s \varnothing$, Fures $\varnothing$, and Ringen with emphasis on clinical symptoms and their relation to previous exposure to bird schistosome cercariae. In 2020, 2 patients from Fures $\varnothing$ suffered from different severity of clinical symptoms after morning bathing in the same lake. We suggest that the differential symptoms may be explained by primary versus secondary exposure to the immunogenic pathogen.

\section{Introduction}

Cercarial dermatitis (also termed swimmer's itch) is a waterborne parasitic skin disease caused by penetration of bird schistosome cercariae into human skin [1]. The causative parasites are digenetic trematodes of the genus Trichobilharzia, which are released from infected freshwater snails into lake water. The disease occurs worldwide but, due to its temperaturedependent development, is more frequent during summer months. These parasites use fresh- 

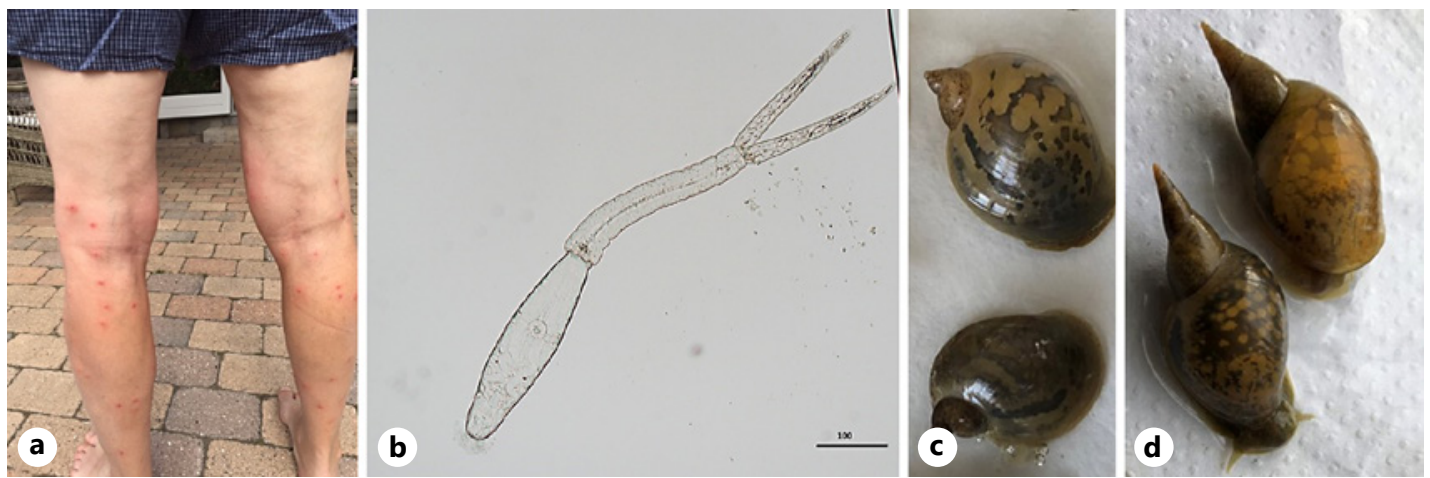

Fig. 1. Skin changes due to swimmer's itch case from Esrum Sø. Photograph provided by the patient (a), Trichobilharzia cercariae released from the freshwater snail Lymnaea stagnalis sampled in lake Ringen Sø (b), Radix balthica sampled from lake Furesø (c), Lymnaea stagnalis collected from lake Ringen Sø, and (d), both were freshwater snails.

water snails and waterfowl as intermediate and final hosts, respectively [2]. Cercariae may penetrate human skin but are not able to complete the life cycle within the human accidental host, and are believed to die soon after penetration. This results in a local inflammation, which typically starts with a tingling or burning sensation and then develops into an itchy maculopapular eruption $[1,3]$. The time from exposure to onset of symptoms varies from a few minutes to a maximum of $24 \mathrm{~h}$ after exposure. Typically, and approximately $1 \mathrm{~h}$ after exposure, the cutaneous lesions begin as a pruritic macular erythematous eruption that progresses to a papular, papulovesicular, and urticarial eruption. The red inflammatory lesions typically cover skin surfaces that have been exposed to water. It peaks within 1-3 days and lasts 1-3 weeks. In cases of repeated exposures, the reaction is often more rapid and severe, indicating sensitization and allergic reactions [4,5]. During recent years, we have observed an increasing occurrence of cercarial dermatitis in Denmark, when recreational bathing activities coincide with release of cercariae from intermediate hosts snails [6, 7]. During the summer 2019 to the end of summer 2020, we studied 5 cases of swimmer's itch. In 2 of the cases, patients exposed to the same lake water at the same time developed different clinical symptoms, and we suggest that previous parasite exposure may exacerbate the symptoms.

\section{Case Reports}

\section{Patient 1-3}

Three cases of cercarial dermatitis were diagnosed by a dermatologist in 2019, and biopsies were taken for histopathology. Patient 1 (75-year-old male) was infected in July 2019 during kayaking/bathing in lake Esrum Sø, and a biopsy was taken 5 days later. The patient presented with a maculopapular rash on abdomen and legs (Fig. 1a) quite similar to insect bite lesions. He had no previous history of cercarial dermatitis. A $4 \mathrm{~mm}$ skin biopsy was taken from his leg 5 days after onset of symptoms. No treatment was applied and the rash disappeared within 3 weeks. Patient 2 and 3 ( 2 middle-age men) had been in contact with water from lake Ringen $\$ \varnothing$ in August 2019 during sampling of biological specimens. Biopsies were taken $48 \mathrm{~h}$ post infection. Patient 2 had a history of previous exposure to cercariae 15 years earlier. No parasites in biopsies were detected microscopically. Skin symptoms remained for 4 weeks. No treatment was used. Patient 3 had no former history of cercarial 


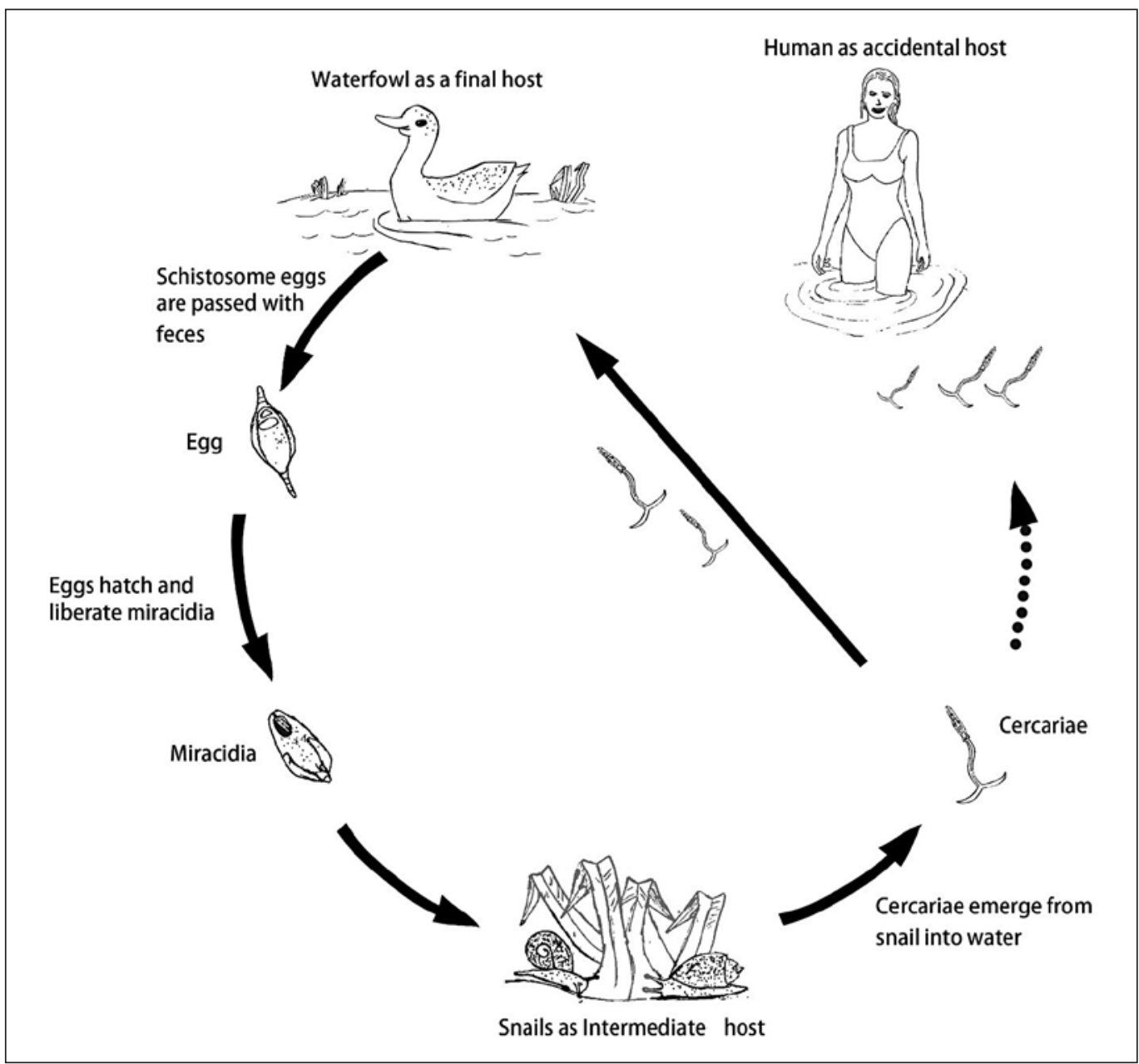

Fig. 2. Avian schistosome life cycle. Illustration by Husam-Aldeen Al-Jubury

dermatitis. A few itchy spots appeared $1 \mathrm{~h}$ post exposure and a maculopapular skin rash developed at exposed skin which continued for 4 days and then disappeared without therapy. Histological slide showed the schistosomula (tissue dwelling cercaria without tail) of Trichobilharzia spp. (Fig. 2).

\section{Patient 4-5}

Two apparently previously healthy female patients (60 and 69 years old, respectively) went swimming in lake Fures $\varnothing$ September 2020. Both patients suffered from a maculopapular skin rash 1-5 days after swimming in the infected lake water. They both felt stinging and prickling in the skin during their swimming which duration $45 \mathrm{~min}$.

The patients described "feeling hot" with worsening of their symptoms the next morning. After $20 \mathrm{~h}$, they experienced a stronger sense of itching and observed papules on their shoulders, arms, and legs.

Patient 4 who reported having a previous exposure developed a severe maculopapular rash located mainly on her arms and legs that were un-covered by the bathing suit. She was treated with fexofenadine $180 \mathrm{mg}$ and topical hydrocortisone. Symptoms continued for 2 weeks. 
Fig. 3. Histological section of a papule (skin from patient's arm). Hematoxylin/eosin stain $\times 5$ with scale bar $100 \mu \mathrm{m}(\mathrm{a}), \times 20$ with scale bar50 $\mu \mathrm{m}$ (b).
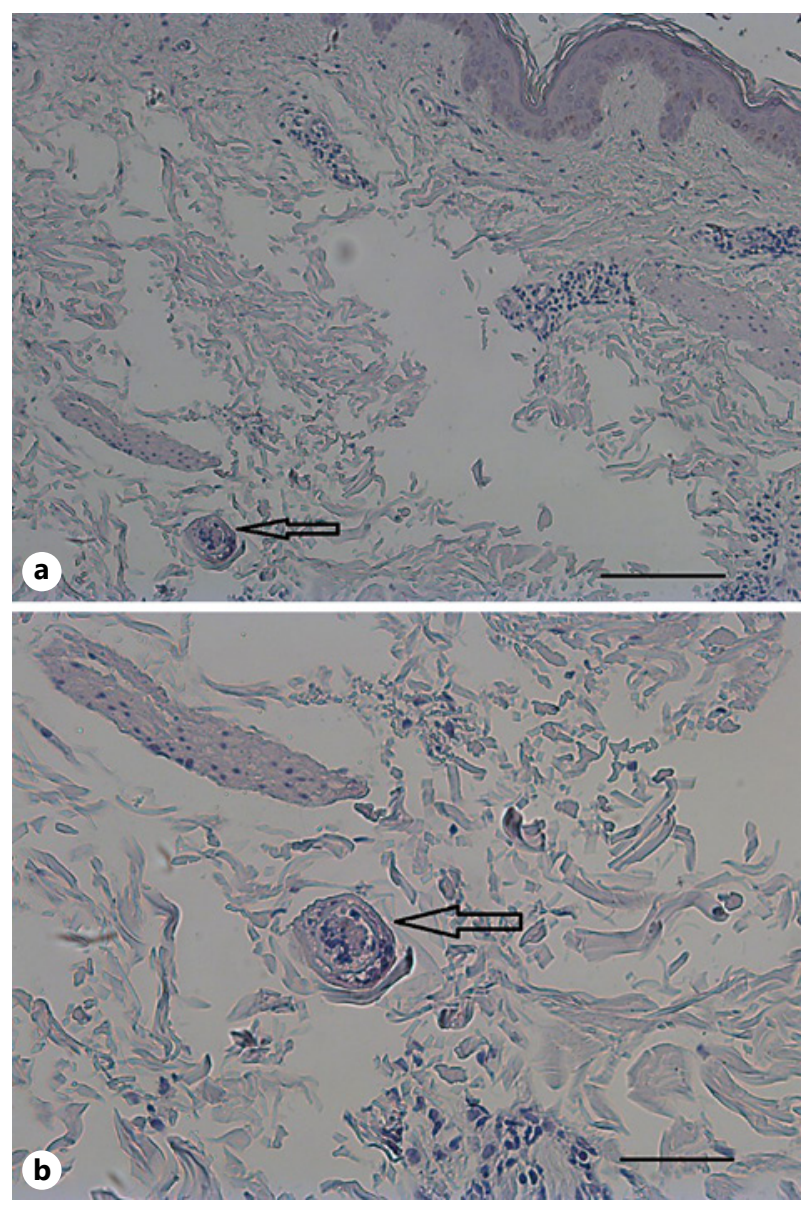

Patient 5, who was known with allergic rhinitis toward pollen and nuts, experienced accompanying fever, headache, and abdominal colicky pain. She was treated with topical zinc ointment and oral cetirizine $10 \mathrm{mg}$.

\section{Discussion}

Cercarial dermatitis or Swimmer's itch is a hypersensitive skin reaction characterized by a pruritic, papular eruption caused by the penetration of the larvae (cercariae) of Trichobilharzia spp. (bird schistosomes) (Fig. 1b) into human skin. Humans are accidental hosts (Fig. 2) [8]. The snail host Radix balthica (Fig. 1c) and Lymnaea stagnalis (Fig. 1d) are confirmed as intermediate host, and they are widespread across Denmark and Europe [9].

The first Danish cases of human cercarial dermatitis were recorded in Hjørring, Jutland in the 1950s [10] although Wesenberg-Lund (1934) [11] much earlier mentioned the occurrence of avian schistosomes in Danish freshwater bodies. Recently, several studies have reported occurrence of bird schistosomes ( $T$. franki, T. regenti, T. szidati, and T. anseri) in several lakes in Denmark $[6,12]$. The summer of 2019 was unusual warm, and recreational places were crowded with bathers and athletes seeking freshwater. We here reported 5 cases of cercarial dermatitis from 2019 to 2020. Patient 1 and 2 both experienced typical symptoms after relevant exposure, but the biopsies could not detect the presence of schistosomules in the skin. This can be explained by the delay of the biopsies $[2,13]$. For it is known from the literature that parasites may be 
eliminated within 2 days [14]. Patient 3 showed cercarial dermatitis and was positive for $T$. szidiati (Fig. 1b). The skin rash disappeared after 1 week. The histological specimen showed the presence of a schistosomule in the dermis (Fig. 3). Previous literature also suggests that the first exposure often leads to a mild skin rash, while a second exposure will develop secondary immune reactions with strong itchy maculopapular eruptions $[4,13,15]$. This is illustrated in patient 4 that reported previous exposure and developed severe maculopapular rash. Patient 2 had also been exposed previously, and this might explain the long-lasting rash of 4 weeks. Why patient 5 besides the typical rash, also developed severe systemic symptoms with fever, malaise, abdominal colic, and headache, it is not known. However, the patient was known to suffer from several allergies, which may influence the reaction and can confound the interpretation. Personal preventive measures can be applied by using swimming suits, protective cream before swimming, avoiding morning hours and shallow waters. The different reactions in the patients described in this case series call for further studies to elucidate the importance of the previous exposure for the development of clinical symptoms. This case series also illuminates a diagnosis, possible treatments and preventive actions, not familiar to all dermatologists.

\section{Conclusion}

We report 5 cases of cercarial dermatitis. Patients were presented with highly different clinical signs. The first 2 patients displayed mild to moderate symptoms. The third patient presented skin rash, and histology showed the presence of a schistosomule in the skin. The fourth patient had a history of previous infection exposure and developed severe maculopapular rash, while the fifth patient, in addition to skin rash, reported severe systemic symptoms. The different reactions in the patients described in this case series call for further studies to elucidate the importance of previous exposure for the development of clinical symptoms.

\section{Statement of Ethics}

This study was conducted in adherence to the World Medical Association Declaration of Helsinki. "Written informed consent was obtained from the patient for publication of the details of their medical case and any accompanying images."

\section{Conflict of Interest Statement}

The authors declare that they have no conflicts of interest.

\section{Funding Sources}

The authors did not receive any funding.

\section{Author Contributions}

A.A. and K.B. designed the study in collaboration with A.B. A.A., E.S.T., and C.N.K. collected the samples and performed the laboratory and data analyses. K.B. and A.B. coordinated the study. All the authors interpreted the results, drafted, read, and approved the final manuscript. 


\section{References}

1 Tracz ES, Al-Jubury A, Buchmann K, Bygum A. Outbreak of swimmer's itch in Denmark. Acta Derm Venereol. 2019 Aug;99:1116-20.

2 Horák P, Kolárová L, Adema CM. Biology of the schistosome genus Trichobilharzia. Adv Parasitol. 2002 Feb; 52:155-233.

3 Haas W, Van de Roemer A. Invasion of the vertebrate skin by cercariae of Trichobilharzia ocellata: penetration processes and stimulating host signals. Parasitol Res. 1998;84:787-95.

4 Kolárová L, Horák P, Skírnisson K, Marečková H, Doenhoff M. Cercarial dermatitis, a neglected allergic disease. Clin Rev Allergy Immunol. 2013 Aug;45:63-74.

5 Ley Vesque B, Giovenazzo P, Guerrier P, Laverdire D, Prud'home H. Investigation of an outbreak of cercarial dermatitis. Epidemiol Infect. 2002 Apr;129:379-86.

6 Al-Jubury A, Kania P, Bygum A, Buchmann K. Temperature and light effects on Trichobilharzia szidati cercariae with implications for a risk analysis. Acta Vet Scand. 2020 Aug;62:54.

7 Larsen A, Bresciani J, Buchmann K. Increasing frequency of cercarial dermatitis at higher latitudes. Acta Parasitol. 2004;49:217-21.

8 Gulyas K, Soldanova M, Orosova M, Oros M. Confirmation of the presence of zoonotic Trichobilharzia franki following a human cercarial dermatitis outbreak in recreational water in Slovakia. Parasitol Res. 2020 Jun; 119:2531-7.

9 Horák P, Mikeš L, Lichtenbergová L, Skála V, Soldánová M, Brant SV. Avian schistosomes and outbreaks of cercarial Dermatitis. Clin Microbiol Rev. 2015 Jan;28(1):165-90.

10 Berg K, Reiter HFH. Observations on schistosome dermatitis in Denmark. Acta Derm Venereol. 1960;40:36980.

11 Wesenberg-Lund C. Contributions to the development of the Trematoda Digenea. Part II. The biology of the freshwater Cercariae in Danish fresh-waters Memoires de 1. Academic Royale des Sciences et des Lettres de Danemark Section des Sciences; 1934. Vol. 5. p. 1-223.

12 Al-Jubury A, Duan Y, Kania PW, Tracz ES, Bygum A, Jørgensen LVG, et al. Avian schistosome species in Danish freshwater lakes: relation to biotic and abiotic factors. J Helminthol. 2021 Apr;95:e22.

13 Haemmerli VU. Schistosomen-Dermatitis am Ziirichsee. Dermatolo. 1953.

14 Macháček T, Turjanicová L, Bulantová J, Hrdý J, Horák P, Mikeš L. Cercarial dermatitis: a systematic follow-up study of human cases with implications for diagnostics. Parasitol Res. 2018 Oct;117:3881-95.

15 Olivier L. Schistosome dermatitis, a sensitization phenomenon. Am J Hyg. 1949;49:290-302. 